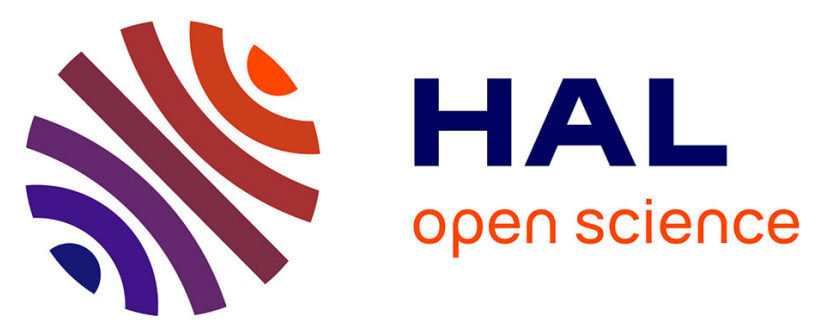

\title{
Forest Dieback, a Tangible Proof of Climate Change? A Cross-Comparison of Forest Stakeholders' Perceptions and Strategies in the Mountain Forests of Europe and China
}

Philippe Deuffic, Mareike Garms, Jun He, Elodie Brahic, Hua Yang, Marius

Mayer

\section{To cite this version:}

Philippe Deuffic, Mareike Garms, Jun He, Elodie Brahic, Hua Yang, et al.. Forest Dieback, a Tangible Proof of Climate Change? A Cross-Comparison of Forest Stakeholders' Perceptions and Strategies in the Mountain Forests of Europe and China. Environmental Management, 2020, 66 (5), pp.858-872. 10.1007/s00267-020-01363-9 . hal-02997849

\section{HAL Id: hal-02997849 \\ https://hal.inrae.fr/hal-02997849}

Submitted on 10 Nov 2020

HAL is a multi-disciplinary open access archive for the deposit and dissemination of scientific research documents, whether they are published or not. The documents may come from teaching and research institutions in France or abroad, or from public or private research centers.
L'archive ouverte pluridisciplinaire HAL, est destinée au dépôt et à la diffusion de documents scientifiques de niveau recherche, publiés ou non, émanant des établissements d'enseignement et de recherche français ou étrangers, des laboratoires publics ou privés. 
Forest Dieback, a Tangible Proof of Climate Change? A CrossComparison of Forest Stakeholders' Perceptions and Strategies in the Mountain Forests of Europe and China

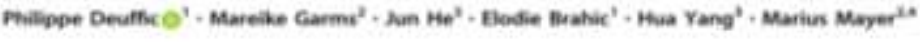

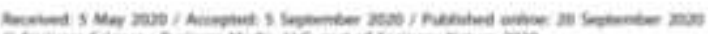

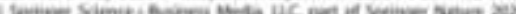

Abstract

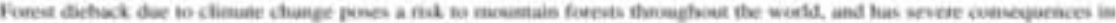

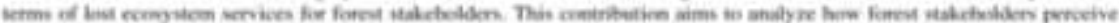

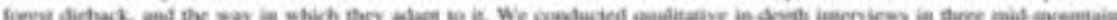

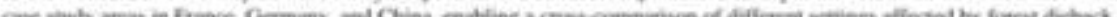

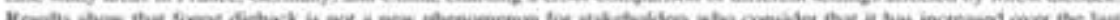

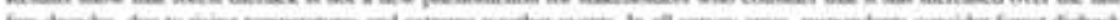

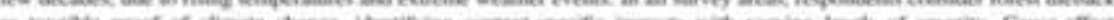

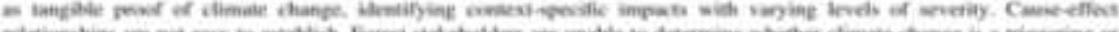

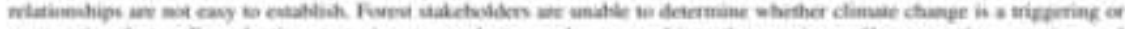

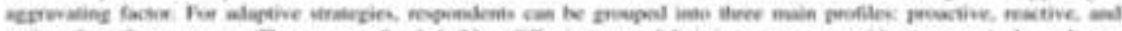

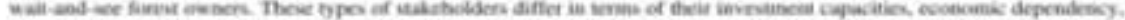

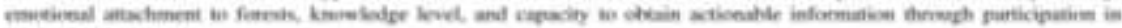

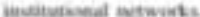

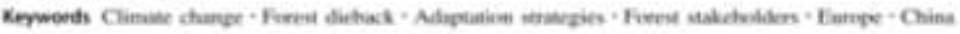

1. Corresponding author ; Philippe Deuffic, INRAE, ETBX, 50 avenue de Verdun Gazinet, F-33612 Cestas cedex, France, philippe.deuffic@inrae.fr tel :+33 557890838

2. Mareike Garms, Greifswald University, Institute of Geography and Geology, Friedrich-Ludwig-Jahn-Str. 17a, 17487 Greifswald, Germany, mareike.garms@uni-greifswald.de

3. Jun He, School of Ethnology and Sociology, Yunnan University, 650092, Kunming, China, jun.he@ynu.edu.cn

4. Elodie Brahic, INRAE, ETBX, 50 avenue de Verdun Gazinet, F-33612 Cestas cedex, France, elodie.brahic@inrae.fr

5. Hua Yang, School of Ethnology and Sociology, Yunnan University, 650092, Kunming, China, huayang@ynu.edu.cn

6. Marius Mayer,

- Innsbruck University, Department of Strategic Management, Marketing and Tourism (Team SME and Tourism), Faculty of Business and Management, Karl-Rahner-Platz 3, 6020 Innsbruck, Austria, marius.mayer@uibk.ac.at

- Greifswald University, Institute of Geography and Geology, Friedrich-Ludwig-Jahn-Str. 17a, 17487 Greifswald, Germany 
Abstract

26

Forest dieback due to climate change poses a risk to mountain forests throughout the world, and has severe consequences in terms of lost ecosystem services for forest stakeholders. This contribution aims to analyze how forest stakeholders perceive forest dieback, and the way in which they adapt to it. We conducted qualitative in-depth interviews in three midmountain case study areas in France, Germany and China, enabling a cross-comparison of different settings affected by forest dieback. Results show that forest dieback is not a new phenomenon for stakeholders who consider that it has increased over the last few decades, due to rising temperatures and extreme weather events. In all survey areas, respondents consider forest dieback as tangible proof of climate change, identifying context-specific impacts with varying levels of severity. Cause-effect relationships are not easy to establish. Forest stakeholders are unable to determine whether climate change is a triggering or aggravating factor. For adaptive strategies, respondents can be grouped into three main profiles: proactive, reactive and wait-and-see forest stakeholders. These types of stakeholders differ in terms of their investment capacities, economic dependency, emotional attachment to forests, knowledge level, and capacity to obtain actionable information through participation in institutional networks.

\section{Keywords}

Climate change, forest dieback, adaptation strategies, forest stakeholders, Europe, China 


\section{Introduction}

Climate change significantly affects the ecological and economic viability of forests, and contributes to changes in tree species patterns around the world (IPCC 2014). Over the next few decades, tree dieback and mortality are projected to increase in many regions due to higher temperatures and prolonged drought (Allen et al. 2010). These impacts are more pronounced in mountainous areas, which experience higher temperature increases (Lindner et al. 2010). However, what actually-constitutes forest dieback is a source of some debate.

For some scholars, tree growth on water-limited sites, species distribution, and the structure of mountain forests are expected to change dramatically (Lindner et al. 2014). Coverage of cold-resistant conifers is projected to decrease significantly, replaced by broadleaf species better able to resist drought conditions (EAA (European Environment Agency) 2017). Goods and services provided by mountain forests, such as carbon storage, biodiversity, water storage, protection against natural hazards, and cultural services will also be negatively impacted (Hansen et al. 2001; Millar et al. 2007). On the contrary, some other scholars identify opportunities, such as improved tree growth (Kellomäki et al. 1997), northward expansion of some tree species (Dullinger et al. 2005), and the rise of tree lines in altitude (Rubel et al. 2017). Saproxylic biodiversity may also profit from climate-induced forest dieback due to a growing stock of deadwood (Müller and Bütler 2010; Seibold et al. 2016). . However, some studies show that deadwood is rarely appreciated by forest owners and the public (Deuffic and Lyser 2012; Gundersen and Frivold 2011 ).

Beyond its impact on ecosystems, forest dieback also affects forest owners' incomes, timber supply for wood-dependent industries, and the provision of ecosystem services for gatherers, hunters, tourism stakeholders, and visitors. Because forest dieback and its impacts in time and space are often hard to predict and assess, forest stakeholders face challenges in adapting their silvicultural models. While forest owners' awareness of climate change is growing in Europe (Sousa-Silva et al. 2018), scientific debates, paradoxical injunctions, and contending messages by forest experts hamper the adoption of adaptive strategies. On the other hand, the strength of belief in local effects and personal experiences of climate change have strong explanatory power (Broomell et al. 2015). Both of these aspects may therefore accurately predict adaptation to climate change (Blennow 2012). 
Even when forest owners link both phenomena, they often focus on the impact on timber production and associated economic losses, rather than biodiversity loss (Takala et al. 2019). Accordingly, strategies that promote the conservation of decaying forests for biodiversity may conflict with more pro-active solutions such as salvage logging, biofuels harvesting and tree species change. Forest owners may also choose very different strategies, ranging from non-adaptation, mal-adaptation, reactive adaptation and exceptionally radical changes (Grothmann and Patt 2005; Sousa-Silva et al. 2018).

While many previous studies have investigated forest stakeholders' attitudes towards climate change, our study is innovative in that it specifically deals with forest dieback. In the past, perception of dieback has been studied through pest outbreaks (McFarlane and Witson 2008) on a limited number of species such as spruce (Chang et al. 2009) or ash (Fellenor et al. 2018; Marzano et al. 2019). Furthermore, no survey has examined in depth whether forest stakeholders attribute forest dieback to climate change. Contrary to abrupt natural hazards such as windthrows, fires, or ice storms, forest dieback is a "slow-onset disaster". Forest stakeholders have difficulties coping with this, because its tangible signs may be visible only months or years later. In theory, gradual hazards such as forest dieback should be easier to manage than unexpected ones. Slow-onset hazards provide more lead-in time, giving greater opportunity to employ proactive responses to mitigate their impacts (StaupeDelgado 2019). We assume that warnings often go unheard, and responses are put on hold until impacts become harmful. To explore how forest owners deal with these weak signals, and how they manage conflicting advice about the appropriate strategies to adopt, we carried out qualitative interviews with forest stakeholders, including forest owners, forest managers, and representatives of forest authorities in three mid-mountainous regions that were comparable but not totally identical in terms of their ecological, socio-economic and cultural conditions: the Pyrenees Mountains (France), the Bavarian Forest (Germany) and the Lijiang mountains in Yunnan (China). To identify similarities and differences in perceptions of forest dieback and adaptive strategies, we explored the following research questions: What signs of forest dieback do direct forest stakeholders perceive and how do they explain this phenomenon? In what way (if at all) are they affected by this phenomenon, and what could be their adaptation strategies? 


\section{Theoretical framework}

Social scientists' contributions to the study of climate change adaptation have transcended a number of disciplines. Geographers and anthropologists have identified many ways in which traditional practices allow for greater adaptive capacity. They showed how a disruption of social cohesion reduces people's adaptive capacity, making them less resilient to environmental stress (Adger 2003). Economists have developed indicators for adaptive capacity, proposing robust decision-making models (Radke et al. 2017), although examples of robust adaptation in forestry literature remain scarce (Yousefpour et al. 2017). Many studies in the field of forestry have shown that economic losses alone do not lead automatically to major changes (Lidskog and Sjödin 2014; Nelson 2007), as such losses tend themselves to adversely impact adaptive capacities. In the field of risk perception, psychologists such as Slovic (1987) made major contributions to the psychometric paradigm of risk perception, showing that risk levels depend on the individuals' personal beliefs and emotions relating to a specific risk. However, many of the risk perception measures employed in survey research with human subjects are either too broad and generic in nature, or focused too narrowly on an individual component of risk (Wilson et al. 2019). For Grothmann and Patt (2005), most of these studies have so far neglected the cognitive dimension of adaptation to climate change, and have failed to consider motivation and perceived adaptive capacity. To address this shortcoming, they propose a socio-cognitive model of adaptation and adaptive capacity that compensates for the weaknesses of adaptation theorizing from a cognitive perspective. To analyze whether forest stakeholders link forest dieback to climate change, how they perceive this risk, and what capacities they have to cope with these types of events, we first mobilize Grothmann and Patt's model, that we complement with Risbey et al's (1999) time-related approach.

In the socio-cognitive Model of Private Proactive Adaptation to Climate Change (MPPACC, Fig.1), Grothmann and Patt (2005) consider both risk perception and perceived adaptive capacity. Risk perception expresses the perceived probability of being exposed to climate change impacts, whereas risk appraisal refers to the assessment of a threat's probability and damage potential (perceived severity). From this perspective, our case studies are original, as severity is hard to assess, given that nobody knows if and when forest dieback will stop or start again. The MPPAC framework also introduces the perceived adaptive capacity, i.e. the 
individual ability to avoid being harmed, along with the costs of action. The perceived adaptive capacity has three subcomponents: 1) the person's perceived adaptation efficacy, i.e., the belief of being effective in protecting oneself or others from being harmed, 2) perceived self-efficacy, referring to the person's perceived ability to carry out adaptive responses, and 3) perceived adaptation costs. Grothmann and Patt (2005) also make a distinction between two types of responses to climate change: adaptation and maladaptation. Adaptive responses prevent damage and occur if risk perception and perceived adaptive capacity are high. Maladaptation includes avoidant and wrong reactions (e.g., denial of the threat, wishful thinking, fatalism), and unintentionally increase damage.

Figure 1: Model of private proactive adaptation to climate change (MPPACC), Source: own draft, adapted from Grothmann \& Patt (2005) and Risbey et al. (1999)

To assess some of the MPPACC steps, we also mobilize the analytical grid by Risbey et al. (1999) who identified four stages: 1) Signal detection through definition of thresholds and alert procedures are essential with slow-onset hazards such as forest dieback, as the first signs may be considered as "noise" and ignored before there has been any effective warning; 2) Evaluation describes how the signal is interpreted and how its foreseeable consequences are evaluated by the system controller (e.g. forest owners); 3) Decision and response, resulting in a change in behavior; 4) Feedback involves monitoring of decision outcomes.

\section{Materials and methods}

Because mountain regions are sentinels of climate change, we selected three different cases, located in mid-mountains, with comparable bioclimatic contexts, coniferous forests, and where forest dieback has occurred in the last few decades (table 1a). All these forests are managed for timber production and provide the same kind of amenities (hunting, gathering, recreation, etc.) to forest owners and local communities. The first case study area (CSA) is the Pays de Sault in the Pyrenees (Southwestern France) where the main tree species is Silver fir (Abies alba) ( $37 \%$ of surface area), used essentially for high quality timber production, based on an uneven-aged model and long rotation cycles (120-150 y.o.). Other 
species are beech (Fagus sylvatica, 24\% of the forest cover), Scots pines (Pinus sylvestris) and oak (Quercus pubescens). In 2003, a severe drought hit Silver firs, which died off dramatically over the four following years (Cailleret et al. 2014). The second CSA is the Bavarian Forest (South-eastern Germany) where Norway spruce (Picea abies) is largely predominant (60\%) over Beech (Fagus sylvatica) and Fir (Abies alba). Managed as a monoculture and planted in shallow soils, spruce populations were significantly damaged by storms in 1983/84, 1999, and 2007, a severe drought in 2003, and recurrent bark beetle outbreaks since the early 1990s (Lausch et al. 2013). The third CSA is the Lijiang prefecture in Yunnan (China) where a specific and non-native variety of Yunnan pines (Pinus yunnanensis var. pygmaea) was introduced forty years ago to limit the impact of erosion and ease pressure on native oak forests (Quercus aquifolioides) that are harvested for fuelwood. However, since 2009, large number of Yunnan pines have been dying from drought and pest outbreaks.

The cross-comparison of these three CSAs, is relevant, as they are characterized by a dominant conifer belonging to the same family (Pinaceae), surrounded by rather similar broadleaves (Fagus or Quercus), and managed for timber production (high quality timber or fuelwood).

We used qualitative in-depth interviews to understand forest stakeholders' values, objectives, motivations, practices, and adaptive strategies. In total, 90 forest stakeholders, including forest owners, were interviewed between 2016 and 2018 (table 1).

We combined two samplings methods: Maximum variation sampling (Miles et al. 2013), aimed at selecting interviewees with a wide range of variation in dimensions of interest (respondents living in different social, economic and political communities and diversely impacted by forest dieback), and snowball sampling (Palinkas et al. 2015), which begins by identifying forest representatives, whom we asked to provide other useful informants. Additional names were obtained via these chain referrals, belonging to different forest community networks. Unlike quantitative surveys, our aim is not to achieve a representative sample of the target population, but to identify its diversity, and to achieve "information 
saturation" (Mason 2010; Strauss and Corbin 1994 ). The point of saturation was reached when new information was no longer forthcoming, and the evidence indicated that all relevant categories of stakeholders had been sampled. A common interview guide was created, consisting of five parts: 1) forestry objectives and forest management practices, 2) damage observed over the last three decades, 3) impacts of forest dieback on biodiversity, 4) adaptation strategies for the future, and 5) socio-demographic data. After transcription, we categorized the key topics coming out of the interviews (Miles et al. 2013). Following this, we wrote analytical memos for each case study to identify the diversity of forest management practices, the perception of forest dieback, their responsiveness to climate change, and their strategies for the future.

As interviewees opted for very different adaptive forest management orientations, ranging from business-as-usual to transformative strategies, we decided to build a typology of adaptation behaviors. This typology is based on influential structural variables and logics of action that are commonly found in forest owners' typologies (Deuffic et al. 2018; Ficko et al. 2019; Van Herzele and Van Gossum 2008; Weiss et al. 2019) and attitudes towards climate change (André et al. 2017; Blennow et al. 2012; Lodin et al. 2020; Van Gameren and Zaccai 2015):

- Perception of climate change: In line with the MPPACC model, respondents consider the perceived probability and severity of future events diversely. Whereas some stakeholders think climate changes will be progressive and manageable, others fear that

- Forest stakeholders' management objectives related to their perceived adaptive extreme climatic events will severely hit local ecosystems and the forests contained therein. capacity: Forest stakeholders need to find a balance between their objectives (economic benefits and commodity production, consumption (wood vs. non-wood services)), their investment capacity, and possible state aid (subsidies, tax relief). These different objectives lead them to select specific forest management models, ranging from no management, to close-to-nature forestry, even-aged forestry, short-rotation, etc.;

- Adaptation intention: Forest stakeholders' intentions to adapt are very diverse (Van Gameren and Zaccai 2015) and vary between proactive anticipation of the next natural 
hazard, reactive responses (acting only once a catastrophe has occurred), ignorance of threats, and procrastination;

- Membership of (in)formal forestry networks: Forest stakeholders are often overwhelmed by contradictory information about climatic trends and the robustness of solutions. As information can be uncertain and ambiguous, participation in social networks may be helpful to make final decisions (André et al. 2017). In such arenas, they can find key informants and heuristics of decision, often based on trust in network participants.

\section{Results}

\subsection{Perceiving signs of forest dieback: a tricky process}

Forest dieback is defined as tree mortality noticeably above usual levels (Allen et al. 2010). However, the identification of lethal and above-average signs of a slow-onset natural hazard may be a tricky process. Confirming such a prognosis requires a fine sense of observation.

In France, interviewees mentioned that Silver firs have always been hit by natural hazards, as the conditions in which they are planted tend to be either cold and mountainous or dry and Mediterranean. While most of these past events have now been forgotten about, some specific events are clearly remembered. For example, older respondents recall that Silver firs suffered from a severe drought after World War II:

"In 1948, I was cutting trees in the forest. For three years, there was a severe drought. It was dreadful, particularly for the municipal forest that grew on poor calcareous soils. Firs were drying, it was terrible, and trees were red, so red!" (P16, retired forester, 85 y.o.).

These memories helped them to more rapidly identify the first signs of a massive forest dieback: in spring 2004, where firs turned red, needles fell, and standing trees died. The event lasted until 2007. A damage assessment was carried out that year by local forest experts which focused much more on public forests ( $45 \%$ of the impacted surface) than private forests, for which data are still missing. Because these smaller private forests are scattered over a larger area, each with their own set of soil and exposure conditions, identifying fir dieback is much more difficult. 
Forest dieback was a "catastrophic event" both at local and regional level, with the surface area and volume of timber lost reaching 5,500 ha and $94,000 \mathrm{~m}^{3}$ respectively. However, at national level, it was considered a "local and minor incident" by forest authorities.

In Germany, forest dieback is not a new phenomenon either. In the 1980 s a debate about 'Waldsterben' (a German term for forest dieback) dominated discourse about forest damage. (Der Spiegel 1981). Most of the interviewees remembered this crisis, as it impacted a large part of the German forests, on both sides of the "Iron Curtain" that divided Germany at that time:

In the Erzgebirge [mountainous region in the east of Germany] even Spruce died. One really feared doom scenarios for our forest during this time, we feared that the forest would be gone as it [Waldsterben] went on." (B1, representative of forest department, 53 y.o)

The most likely cause of Waldsterben was a complex disease triggered by cumulative stresses from increased air pollution. Forty years later, for respondents, air pollution is no longer the main cause of forest dieback, as they now tend to connect this phenomenon with extreme weather conditions (e.g. drought, storms). While storm damage is immediately tangible, pests and diseases emerge later and over a longer time frame. Because disease detection and tree removal are legal obligations, monitoring of pest outbreaks is timeconsuming and calls for specific knowledge. Forest owners often detect bark beetle outbreaks too late, and consider them to be a never-ending story:

"When it comes to pest management in the private forest, you always lag behind the [bark] beetle. And it would be presumptuous to say that you can do something against it. We are $f^{*} c k e d$ when it [bark beetle season] starts. Nothing more to say." (B16, representative of forest owner association, 33 y.o.)

In China, most respondents recalled the severe drought of 2010-2012 and the resulting forest dieback. Since then droughts, have tended to be episodic and recurrent, especially over the last five years. However, areas affected by forest dieback are spread broadly across the landscape and forest stakeholders are often unable to measure the affected area with any level of precision. However, they identify the primary signs of dieback as leaves turning yellow from March to May, before the arrival of the monsoon season. While seasonality helps them to detect the primary signs of dieback, its severity is hard to forecast. For local state forest officers, young Yunnan pines seem to be less resistant to drought than older 
ones, but are also better able to regrow if rain falls in time. Due to the indeterminate duration of the event, interviewees struggle to assess tree resilience to drought. A local forest officer states:

"We are not sure if the tree is really dying, as it grows again in the rainy season. The problem is that even if the trees seem to die and then grow again, eventually there is not actual growth in height and volume". (Y14, forest officer, 60 y.o.)

Another observed sign of dieback is the increasing amount of pests during the dry season. Local people think that drought results in forest dieback, which in turn leads to pest outbreaks. This phenomenon is particularly recognized by local forest users, since broadleaves have been replaced by Yunnan pine monocultures. Unfortunately, the specific variety of Pinus yunannensis var pygmaea used for afforestation later turned out to be very sensitive to pests.

\subsection{Climate change, a plausible explanation for forest dieback?}

Attribution of causes is important as it allows victims of natural hazards to endow events with meaning. In our CSAs, none of the incidents of forest dieback were considered to be "acts of God", as this would imply that nothing could have been done to prevent them. Respondents regard forest dieback as mainly "acts of Nature", and to a lesser extent, "acts of human beings", which implies blaming specific groups (e.g. forest experts) and potentially the decisions taken by forest managers. While climate change would appear to be an ideal culprit, some interviewees also question the role of humans, especially decisions made in the field of forest management in the past.

In the French CSA, interviewees provided mixed opinions relating to natural or human causes of forest dieback. While they point to the prolonged period of drought as a trigger, they also highlight the soil and spatial pre-conditions, especially the tree line zonation, the lack of water on limestone, and the south-facing exposure that dries up forest stands. Other factors are more discussed, as they directly question past human decision-making. For the production-oriented experts, dying trees were often too old (>120 years) and should have been harvested decades earlier. On the other hand, environmentalists argue that healthy trees can reach 300 years with no signs of decay. A second debate centers around forestry techniques: for environmentalists, regular and even-aged forest stands are more sensitive to 
natural hazards. Understorey management may also mitigate or accelerate forest dieback, as it can be both an ally and a competitor for water depending on its density. However, local forest experts opted for intensive clearing of understorey vegetation. This action dramatically decreased the humidity level and exacerbated the effects of direct sun exposure. Despite these contrasting viewpoints, the consensus would appear to be that forest dieback is a consequence of climate change:

«For the first time in our lives we saw that the grasslands were drying up dramatically in spring. Then, in the autumn, trees were turning red and six months later they died. Finally, we made the connection with climate change (P28, farmer and forest owner, 59 y.o.).

While interviewees admit that winters are milder with far less snow than four decades ago, they have difficulty with other trends, such as growing Mediterranean influences for the future. For them, interannual changes in weather are still too significant for them to admit that there is a real change in climate conditions, even if they clearly see that tree lines are rising up.

In Germany, forest stakeholders explained dieback through a mix of abiotic (storms) and biotic factors (pests and diseases) on Norway spruce (Picea abies). However, this fast growing and economically important tree species was planted in large-scale monocultures, which later proved not to be entirely sustainable and forest stakeholders actually admit that spruces should not have been planted in this way. Because of a shallow root system, respondents identify water availability as a limiting factor. This species is also very sensitive to pests. Due to higher temperatures, bark beetles start to breed in early spring, resulting in several generations per year. Once a forest is impacted, interviewees emphasize that early detection and fast removal of infested trees are essential, - as required by a Bavarian legal regulation. However, the first indications of infestation symptoms are not obvious and require accurate knowledge to identify. Most private forest owners tend therefore to detect bark beetles too late. On the other hand, a few overcautious forest owners start to harvest trees, even if they are unsure about an infestation. In both cases, pest outbreaks always mean economic losses.

"This is the bread tree of the Bavarian Forest. But someone forgot to say that it is [also] the bread tree for the bark beetle." (B8, NGO employee, 47 y.o). 
German respondents also notice that present outbreaks are becoming worse with current changes in climatic conditions (mild winters and more extreme weather). They also connect these changes to new forest dynamics, such as a longer vegetation period, later frost damage on sprouting foliage, drought stress, and a rising tree line for beeches. While climate change is gradually becoming accepted as a possible cause for forest dieback, the causeeffect relationships are not straightforward. For instance, forest stakeholders are unable to determine whether climate change is a triggering or an aggravating factor for bark beetle outbreaks, given that soil conditions, silvicultural models, and tree species also influence the level of damage. However, interviewees notice that the combination of factors has mutuallyintensifying effects. Another problem is the unpredictable severity of extreme weather events that reinforces uncertainty:

In China, most interviewees notice that drought has resulted in forest dieback, especially over the last ten years. They also state that the climate pattern is becoming more irregular, with less rainfall during the dry season, and heavier precipitation during the rainy season. Some villagers also observed that glaciers are melting, inducing a lack of water supply during spring. As these changes in climate patterns are beyond their control, they point out that afforestation has increased competition for water resources, meaning that the impacts of drought are - at least partly - of human origin:

Other purely human causes are also suggested by local forest officers, who argue that farmers changed the forest structure by harvesting oak for fuelwood. Forest authorities launched a large-scale afforestation program in the 1980s to compensate for this. Yunnan Pine was selected to ensure a fast recovery of fallow lands and decaying forests. While it has become the dominant species, pest damage has soared and left forest authorities in an intractable situation: 
"We do not encourage investing in Yunnan Pine plantation anymore because pest and drought have much more effect on Yunnan Pine now than by the past. (forest officer, 50 y.o).

Forest officers grudgingly admit that the non-native variety of Yunnan pine ( $P$. yunnanensis var pygmaea) turned out to be more sensitive to pests than the local species ( $P$. yunnanensis). While they feel partly responsible for this bad decision, they also consider that the collection of dead wood by local residents aggravates pest dissemination and contamination of healthy trees during return transport. They would prefer that people burn dead wood on site and transform it into charcoal. However, current regulations are not sufficient to dissuade gatherers of dead wood from applying this recommendation.

\subsection{The impact of forest dieback on forest communities}

Since forest dieback has spread over four years, economic losses have been severe for French forest owners. First, the wood market became saturated, with prices dropping by around $60 \%$. Second, consumers abandoned Silver fir in favour of new species such as Douglas fir. Third, while decaying Silver firs were transformed into pallets in the past, other tree species are now preferred. However, the impacts were not identical for all interviewees. Public forest managers sold most of their decaying trees just before market congestion began to be felt. They also offered large and easy-to-harvest volumes to forest enterprises and sawmills outside the CSA. By contrast, small-scale forest owners were often not integrated into any professional networks, and were hence not used to negotiating with contractors. Because of the small size of their properties, coupled with prohibitive transport costs, private forest owners had difficulty finding foresters.

"Financially, what we got from these dead trees was almost nothing. Forest companies gave us what they wanted. It was between 10 and $15 €$ or nothing..." (P26, forest owner, 65 y.o.)

These losses have not been compensated by any financial support from the state and have had long-term fallouts. Forest owners are very reluctant to invest again, as many have lost their savings, as well as their ability to reinvest, due to the collapse in price.

In the German CSA, it is not easy to quantify forest damage in recent times, as pest outbreaks and other natural hazards have accumulated over several years. A state forest manager reported that there had been no regular harvest over the last few years, because of 
a large pre-existing volume of infested wood. While regional sawmills are overloaded, forest owner associations are overstretched, and timber prices have declined rapidly. Regular logging and sales volumes are almost impossible to forecast. In 2017, storm "Kolle" produced an additional 2.3 million $\mathrm{m}^{3}$ in damaged wood with estimated costs of 100 Million Euros. The economic losses for forest owners have been partially compensated by the state through financial support, tax reliefs and interest-free loans. In the aftermath, the Bavarian forestry minister initiated the program "Forest modification 2030" which helps to replant climate-adapted and mixed forests.

In China, forest dieback does not directly affect people and communities, as they do not rely on forests in terms of timber production or tourism. The use of fuelwood has significantly declined, as villagers move more towards electricity. Furthermore, forests where people collect non-timber products such as mushrooms are not dying. However, interviewees are aware of the symbiotic relationship between fungi and trees, and fear that forest dieback will affect the growth and quality of commercial mushrooms in the mid-term, given that the mushroom harvest may account for 50 to $80 \%$ of their household income (He et al. 2011):

"If trees die, the mushrooms will not grow. The better the trees grow, the better mushrooms grow as well. Mushrooms will also be easier to sell, as they will contain more moisture" (villager, 48 y.o.)

\subsection{Adaptation responses to climate change and forest dieback}

Once interviewees had perceived forest dieback and identified its multidimensional causes, they adopted attitudes were active/passive in nature, depending on influential variables, such as their logic of action (Deuffic et al. 2018; Van Gameren and Zaccai 2015) which is often related to their forest management objectives and priority given to climate change among concerns of forest management, their personal direct observation of events, and their perceived adaptation intention and capacity.

Knowledge in forest management, often related to membership of (in)formal forestry networks and access to key informant people, is also a decisive factor in decision-making as well as the existence of a contingency plan and specific subsidies that can help forest owners overcome the crisis. 


\subsubsection{Proactive forest owners (G1)}

These stakeholders are convinced that climate is changing locally, as they have observed tangible signs over the last decades. These medium to large-scale stakeholders often occupy official positions on the boards of forest institutions. As leaders, they gather information on climate issues and commmunicate them actively. Strongly attached to their forest, they earn a significant part of their living from timber production. Endowed with strong economic and cognitive capacities, they have clear opinions on strategies for coping with forest dieback. However, they opt for opposing strategies.

Subgroup G1a is often pessimistic about the adaptive capacity of local tree species. While these species remain dominant on their property, they consider that water will become a limiting factor in the future. They introduce new species after clear-cuts or salvage logging: Cedar (Cedrus atlantica) in the French Pyrenees; Silver fir (Abies alba) and Douglas fir (Pseudotsuga menziesii) in the German CSA as these species are as productive as spruce and highly valuable on wood markets; and oak (Quercus aquifolioides) to balance the dominance of pine in China.

In contrast, subgroup G1b promotes nature-based solutions (NBS). They rely on integrated pest management (IPM) and natural biological processes to control pest outbreaks. Managing mixed, uneven-aged forests is their forestry standard now and for the future. Instead of trying to escape natural disturbances, they increase forest resilience by mixing stand structures and local thermo-resistant species.

\subsubsection{Reactive forest stakeholders (G2)}

Owning medium to small properties, and well-educated in terms of forestry, G2 forest owners participate in peer group discussions but never take the lead. They do not earn their living from the forests, which they see as part of their personal savings, except in the Chinese CSA, where mushroom picking significantly improves revenues. Adaptative capacities are limited by medium or low economic resources or, in the Chinese CSA, by their lack of empowerment in decision-making. Contrary to G1, their adaptation intention is 
mainly reactive, as they do not anticipate the next extreme event. They prefer to know exactly what the next calamity will be, and act accordingly. Due to different levels of risk adaptation, this group can also be divided into two subgroups.

Sub-group G2a considers that there are no equal alternatives to the dominant local tree species. They simply apply progressive shifts, such as increasing the frequency and intensity of thinning and shortening rotations. They therefore gamble on a belief that harvest benefits will cover the losses incurred between two disturbances. As financial capacities are limited, they cannot afford cost-prohibitive plantations of new tree species.

Subgroup G2b forest owners are less involved in professional networks, and have smaller properties than G2a. Due to their lower level of knowledge, they identify bark beetle infestations later, and copy others to cope with uncertainty (Weber 2010). Salvage logging and rotation shortening are their main adaptation strategies. They also plan to mix trees, but only with local species and in the future as they procrastinate on strategic decisions.

\subsection{3 "Wait and see" forest stakeholders (G3)}

This group consists of small to very small-scale forest owners and users (for the Chinese CSA) who feel less concerned with climate change or who have lost part of their forests in the past. Very low profitability hampers their capacity to act or even react to natural disasters. Often not members of any organizations, they have difficulty learning about pest outbreaks in time, and struggle to find contractors for salvage logging. These adverse conditions hinder the implementation of adaptive solutions. Two main attitudes can be found:

Downhearted and resigned observers (G3a), who have often engaged enthusiastically in forestry in the past, have incurred such high losses emotional stress, that they just wait passively for the next catastrophe to take place, with a hint of fatalism. They do not have enough capacity and willingness to re-invest time and money into an industry which has already deprived them of their savings.

Sub-group (G3b) consists of inactive forest stakeholders who have not managed their forest for a significant period of time. The impact of climate change just confirms their opinion about forestry as a bad business. This attitude is observed especially in the European CSAs. 


\subsection{A global phenomenon with context-specific knock-on effects}

497

498

499

500

501

502

503

504

505

506

507

508

509

510

511

512

513

514

515

516

517

518

519

520

521

522

523

The MPPACC model shows that ecological factors significantly shape forest stakeholders' perception of forest dieback as changing climatic conditions gradually exacerbate their effects. The French and Chinese respondents are fully aware that droughts increase water scarcity, hamper cultivation efforts, and ultimately become a dominating and limiting factor. In Germany and China, interviewees associate deteriorating weather conditions with pest outbreaks. While forest stakeholders in all CSAs are worried about changing ecological conditions for trees and protected wildlife species, they do not care so much about saproxylic fauna and flora - except for mushrooms in the Chinese CSA - as also observed by Dunn (2005). Alongside ecological factors, most forest stakeholders also admit that some forest management decisions, - (e.g. planting in shallow soils, choosing an unsuitable species, opening the forest canopy by thinning) - worsen the effects of dieback. While drought and pest outbreaks are freak events, outside the control of human beings, forest stakeholders admit they have been partly responsible for worsening the effects of those natural hazards. Acknowledging responsibility opens the door to reflexivity, self-criticism, and possibly changes in practices, as forest owners and managers now admit that nature is no longer the one and only culprit.

In all of our CSAs, climate change-induced forest dieback affects the local economy. However, its severity depends on the adaptive capacity and resilience of the wood sector. In Germany, the wood sector is weakened by the multiplicity and additionality of forest damage. Regional forest authorities have set up contingency plans and economic support including incentives for tree diversification with broadleaves, despite demand in the wood market still being centered on conifers. In the French CSA, the economic impact of forest dieback is moderate, since the wood sector has partially recovered from the 2003-2007 drought. Nevertheless, this crisis has changed the landscape of the wood market, as the wood industry gradually shifts from Silver fir to Douglas fir. In China, the economic impact of dieback is considered moderate. Timber is not the main product, and while mushroom quality suffers from changing climate conditions, the resource is still present. 
Social factors have a rather low influence on forest stakeholders' perception in France and China, but a moderate influence in Germany. In the French CSA, the dieback issue was mainly discussed within the forest owners' community. Its presence in the media was limited to regional newspapers. There were no public debates, since solutions were discussed in restricted technocratic arenas. In China, forest management is under the control of local forest authorities, meaning that the local population has very little freedom to steer forest policies. However, forest tenure reforms are slowly being implemented to devolve land-use rights and forest ownership of collective forest areas to individual households (He 2017), offering more possibilities for forest users to discuss adaptive measures. In Germany, agenda setting of forest dieback has been more prevalent, due to the severity and repetition of the crises and the echoing with Waldsterben.

Forest policy makers and the large network of forest owners' associations have also fostered more radical changes in adaptive policies, although there is still room to expand advisory services for adaptation planning. In line with a recent Delphi study (Sacher and Mayer 2019) participating experts clearly identify climate change as the most important influencing factor on forests in Bavaria in the coming decades.

\subsection{A slow-burning crisis with unequal adaptation costs}

Despite the different socio-economic and cultural contexts, a common feeling of insecurity about climate trends emerges among forest stakeholders in the CSAs. Thanks to growing experiences of natural hazards, discussions in peer groups and monitoring by experts, respondents have learned to identify weak signs of forest dieback. They are gradually beginning to connect forest dieback with climate change, and consider that both will likely become more prominent in the future. However, they still have difficulty evaluating the severity of these events, which may or may not cease due to weather variability. This perceived severity also depends on local conditions and the scale of the damage, as signs of forest dieback are dispersed in space and time in France and China, and spread over a large area in Germany.

Forest dieback calls into question the deterministic forest growth models which have led forest stakeholders' behavior up until now (Lawrence 2017). Even the linear timeline proposed by Risbey et al. (1999) is challenged. Contrary to sudden-onset disasters such as 
storms or fires, the signal detection period of forest dieback never ends, and is often intertwined with the next steps (evaluation and decision). Forest dieback looks like a slowburning crisis (Staupe-Delgado 2019). Its elusive and uncertain nature reduces the monitoring vigilance of forest institutions and leads fatigue. When alert thresholds are not always easy to detect, and weak signals are ignored, it takes much longer for the alarm to be raised, particularly when there is no significant complaint from stakeholder groups, and when the issue is present in the media. Because the distinction between dieback and decline is not very clear in the literature (Ciesla and Donaubauer 1994), forest decision-makers produce fragmented responses.

In terms of adaptation costs, offering equitable opportunities for the most disadvantaged forest stakeholders to improve their forest management is a big challenge. For Adger et al. (2009), limits on stakeholders ability to adapt are socially constructed, as they depend on goals, values, risk, social choice, and power structures within society. In all our CSAs, largescale forest owners (e.g. groups G1a and G1b) have better access to information. They can test diverse forestry models by anticipation (before the crisis) or ex-post, on several stands, and with marginal impacts in case of failure. By contrast, small-scale owners (e.g. group $2 b$, $3 a$, and $3 b$ ) with limited economic capacities and poor access to information will not be able to afford high levels of investment in new forestry models. In China, the recurrence of drought weakens mushrooms pickers' activities and leads them to diversify their harvest with alternatives such as nuts, fruits and medicinal herbs (He et al. 2009). Even when institutional support for reforestation exists as in the German CSA, it rarely covers the full costs and never the loss of future value of mature trees. The challenge for forest decisionmakers is to propose solutions, which can be implemented by as many forest owners as possible. Along with financial support, they also need to offer information about these new forestry models to enable informed choices.

\subsection{Adapting through practices}

Once forest stakeholders consider that forest dieback is present, they choose between different adaptive strategies. For two decades, experts have framed general and often nonspecific recommendations that suggest maintaining current ecological patterns in their present state via adaptation (Hagerman and Pelai 2018). However, experts' legitimacy has 
been badly damaged in the three CSAs and the stakeholders could have seriously questioned their recommendations. Despite this, forest owners seem to trust experts overall. As observed by Lidskog and Sjödin (2015) in Sweden, forest experts' epistemic authority - i.e. the legitimacy to define, describe, and explain bounded domains of reality - has been gradually restored. In line with Bulkeley (2000) our study suggests that social networks are strategic arenas where local knowledge, values, and scientific information are assessed to create legitimate understandings. These peer networks are valuable in connecting information about climate risks and opportunities for adaptation to the actual forest property (André et al. 2017). While risk perception is an important precondition for changes in forestry practices, risk adaptation requires trust in informants. Typically for wicked problems like climate change, forest stakeholders' decision-making combines intuitions based on individual experience with explanations offered by actors with high cultural authority (Sarewitz 2011). On this basis, forest stakeholders' decision-making is a mix of confirmed facts (their direct observations), accepted facts (from epistemic authorities they trust), beliefs and perceptions of climate change, forest management objectives, and the norms and values they prioritize (security, profitability, achievement, conformity).

Finally, forest stakeholders often prioritize three main adaptive responses, focusing primarily on maintaining and cautiously adapting existing forest management patterns and processes. Shifting to new system configurations is chosen only when no other solutions are available. The first basic and classic recommendation often found in guidelines for adaptive strategies consists in shortening rotations. While this adaptive practice is often ecologically harmful as it significantly changes the structure of the forest stands (Roberge et al. 2016), it is rather simple to implement by forest owners from a technical point of view and even sometimes profitable. Partially adopted by French and German forest stakeholders, this strategy has also the advantage of being neither constraining nor irreversible as the harvesting decision may be postponed according to the fluctuation of the wood market demand. Moreover, wood sector industrialists also entice forest owners to adopt this practice because they prefer processing wood of low to medium diameters. The second recommendation consists in cultivating a mixed and structured forest. This is not a new concept, but is gaining attention in Germany and France, even if its implementation will require specific information and education programmes for forest owners to enhance their adaptive capacities. The third 
and most transformative recommendation consists in tree species substitution, including displacing decaying trees with new non-local and more resilient species. Often motivated by the definitive decline of timber production, along with the expected rise in their wood price (Hanewinkel et al. 2013), this adaptive strategy is far from being adopted without circumspection. As observed in Sweden and Ireland after severe storms (Deuffic and Ní Dhubháin 2020; Lidskog and Sjödin 2014), some forest stakeholders still regard the traditional tree species as the best option. They are incentivized to maintain these traditional species through nurseries, advisory systems, sawmills and commercial outlets which are often path-dependent on these trees. In China and France, forest stakeholders still believe in the resilience of the traditional tree species against climate change, and new tree species are introduced only for trials on small plots. In contrast, German stakeholders plan to replace Norway spruce with broadleaves in the long-term.

These recommendations seem to lack ambition for Hagerman and Pelaï (2018) who also advocate transformational management pathways. However, for the most transformative pathways, adaptive capacity is crucial, as it depends on context, related both to governance measures and real room for maneuver (Gupta et al. 2010). On the other hand, a lack of adaptive capacity, e.g. insufficient levels of time, money, knowledge, social or institutional support, leads to a weaker adaptation intention. In the German CSA, the adaptation strategy is managed by the regional forest authorities with strong incentives and supports actual transformation of the forest socio-ecosystem in the long term. In France, incentives to change practices mainly come from the key forest economic players, who suggest adopting new practices, not only to adapt to climate change but also to the market demand. This ambiguous and short-term suggestion can be interpreted as a kind of "climate change washing" - in reference to greenwashing - as these dominant stakeholders in the wood sector play on private owners' aversion to risk in order to preserve their own vested interests.

\subsection{Maladaptation, a real but normative issue?}

Our criticism of the MPPACC model mainly concerns the issue of maladaptation. This normative assertion presupposes that some options are better than others. After natural hazards, there is a strong propensity and social pressure to drive major changes. However, 
645 forest stakeholders often fall back into routines and only make slight shifts in their forest management practices (Deuffic and Ní Dhubháin 2020; Lidskog and Sjödin 2014). This raises the question as to whether their decisions are necessarily maladaptive. As noticed by Adger (2009), adaptation decisions taken today and considered as "good", reasonable or rational may have negative impacts for future generations. As soon as the first signs of forest dieback are identified, experts often consider salvage logging as the best options. However, knowing whether to cut down or leave in place trees after a natural hazard is far from easy (Petucco et al. 2020). On the one hand, forest stakeholders who have experienced forest dieback in the past know that ignoring warnings and putting responses on hold often makes impacts unnecessarily costly to reverse. On the other hand, acting too promptly may deprive them of future ecosystem services, as some trees may recover from moderate droughts. The term 'maladaptation' also suggests that forest owners alone are responsible, but the socioeconomic and political context needs to be considered. Forest stakeholders often return to routines because they lack the capacity to implement new forest management models without specific help, such as a relevant information and knowledge system (Lawrence et al. 2020), e.g. financial incentives, etc..

This study suggests adding the unpredictability of events and insecurity of forest stakeholders to the MPPACC model. While extreme weather events are interpreted as tangible signs of climate change, they contribute to a persistent feeling of anxiety. Their slow-onset characteristics make the identification of climate impacts highly unpredictable. Interactions between factors further complicate the identification of causes by forest stakeholders, as they are heavily intertwined. While abiotic stressors such as droughts are often the triggering event, pest outbreaks appear as aggravating and potentially fatal factors.

With regard to the temporal sequences proposed by Risbey et al. (1999), the four steps (detection, evaluation, decision, and feedback) are easily identified in the three CSAs. However, their linearity is questioned by the time-related specificity of forest dieback. Because it is a slow-onset phenomenon, each stage may be reinitialized before the following one. New configurations of events, such as scientific breakthroughs, innovation, and changes in power relations may slow down or accelerate the pace - and even the order - of steps taken in the decision making process. In the German case study, the succession and 
676 intertwinement of hazards made the supposedly linear decision process very difficult to 677 maintain. The additionality of damage resets and progressively reduces the adaptive 678 capacity of the most fragile forest stakeholders such as small-scale forest owners and 679 sawmills.

680

681

682

683

684

685

686

687

688

689

690

691

692

693

694

695

696

697

698

699

700

701

702

703

\section{Conclusion}

This paper aimed to analyze the perception of forest dieback and adaptive strategies in three mountain forest contexts in France, Germany and China using a qualitative approach. In line with the specific nature of forest dieback as a "slow-onset disaster", we show that forest owners have to deal with weak signals and manage conflicting advice about the appropriate strategies to adopt. For respondents in all CSAs, forest dieback is not a new phenomenon, as they remember similar events in the past. Their observations help them to identify the first signs of a massive forest dieback that they explain as a mixture of abiotic and biotic factors, with climate change as an aggravating factor. The respondents convey uncertainties about cause-effect relationships which are not easy to establish and sometimes controversial.

While all interviewed forest stakeholders are affected by forest dieback, the socio-economic impacts differ. In France, public forest managers could cope with the consequences much better than small-scale forest owners. The economic losses also have long-term impacts, because forest owners are reluctant to re-invest in forestry. In the German CSA, economic impacts are huge, because of congestion in the wood market, and a drop in prices. This triggers public interventions which partially compensate forest owners' economic losses through public financial support. In contrast, in the Chinese CSA current forest dieback does not directly affect local communities, as they do not rely economically on timber.

While a climate change risk appraisal is given exhibited by forest stakeholders in all CSAs, their adaptation appraisal is often insufficient to form an adaptation intention. This is especially the case for small-scale forest owners who perceive their self-efficacy to be low, and the costs of adaptation to be prohibitive. As a result, we recommend strengthening adaptation capacities by providing more information, encouraging greater involvement in social forestry networks, offering financial support to this deprived category. 
In terms of adaptive strategies, respondents can be grouped into three profiles: proactive, reactive and wait-and-see stakeholders. While these groups do not necessarily differ in their belief in climate change, they do vary in terms of their economic investment capacities, economic dependency, emotional attachment to their forests, knowledge level, and participation in institutional networks. Some studies show that promoting local selfgovernance and the participation of external stakeholders in forest management planning or in regional forest or climate change policy adaptation may be a way of overcoming path dependency, behavioral obstacles and potential policy failures in implementing adaptation (Bouriaud et al. 2015). However, our study also underlines that, beyond the mantra of forest user and stakeholder participation, this process may also be surreptitiously influenced by the most powerful and influential participants for their vested interests. Making use of their epistemic authority, they often influence less informed stakeholders.

This study is also prone to limitations typical to qualitative research, as we cannot infer a statistical distribution of profiles to the groups. We suggest a follow-up study with a quantitative research design to test the extent to which these results could be generalized for the CSA, and how stakeholders are distributed into the identified groups. As forest stakeholders only make up a relatively small part of their local communities, it may also be beneficial to assess lay people's attitudes towards forest dieback. Lay people are not forest experts but, once they are mobilized, they may become very influential in decision-making.

\section{Acknowledgements}

This research is part of the international project CLIMTREE "Ecological and Socioeconomic Impacts of Climate-Induced Tree Diebacks in Highland Forests » funded by Belmont Forum Call: "Mountains as Sentinels of Change".

The French section of this research was funded by the French National Research Agency (ANR) under the grant number ANR- 15-MASC-002-01. We thank Laurent Larrieu (INRA), Dominique Micaux (ONF), Alexandre Laizé (Communauté de Communes Pyrénées audoises) and Johnatan de Larminat for their help with interviewees' contacts. 
The German part of this research has been funded by the Deutsche Forschungsgemeinschaft (DFG) under the grant number MA 7249/1-1. The German project team would like to thank Lea Prüß and Michael Sobek for their invaluable help with transcribing the interviews.

The Chinese part of this research has been funded by Ministry of Education of P.R. China (Project No. 16JJD850015) and National Natural Science Foundation of China (Project No. 41661144002).

Conflict of Interest

The authors declare that they have no conflict of interest.

\section{References}

Adger W-N (2003) Social Aspects of adaptive capacity. In: Smith JB, Klein RJT, Huq S (eds) Climate Change, Adaptive Capacity and Development. Imperial College Press, London, pp 29-49. doi:https://doi.org/10.1142/9781860945816 0003

Adger W, Lorenzoni I, O'Brien KL (2009) Adapting to Climate Change: Thresholds, Values, Governance. Cambridge University Press, Cambridge. doi:DOI: 10.1017/CBO9780511596667

Allen CD et al. (2010) A global overview of drought and heat-induced tree mortality reveals emerging climate change risks for forests Forest Ecology and Management 259:660-684 doi:http://dx.doi.org/10.1016/j.foreco.2009.09.001

André K, Baird J, Gerger Swartling Å, Vulturius G, Plummer R (2017) Analysis of Swedish Forest Owners' Information and Knowledge-Sharing Networks for Decision-Making: Insights for Climate Change Communication and Adaptation Environmental Management 59:885-897 doi:http://dx.doi.org/10.1007/s00267-017-0844-1

Blennow K (2012) Adaptation of forest management to climate change among private individual forest owners in Sweden Forest Policy and Economics 24:41-47 doi:http://dx.doi.org/10.1016/j.forpol.2011.04.005

Blennow K, Persson J, Tomé M, Hanewinkel M (2012) Climate Change: Believing and Seeing Implies Adapting PLoS ONE 7:e50182 doi:https://dx.doi.org/10.1371/journal.pone.0050182

Bouriaud L et al. (2015) Institutional factors and opportunities for adapting European forest management to climate change Reg Environ Change 15:1595-1609 doi:https://dx.doi.org/10.1007/s10113-015-0852-8

Broomell SB, Budescu DV, Por H-H (2015) Personal experience with climate change predicts intentions to act Global Environmental Change 32:67-73 doi:https://doi.org/10.1016/j.gloenvcha.2015.03.001

Buckeley H (2000) Common knowledge? Public understanding of climate change in Newcastle, Australia Public Understanding of Science 9:313-333 doi:https://doi.org/10.1177/096366250000900301

Cailleret M, Nourtier M, Amm A, Durand-Gillmann M, Davi H (2014) Drought-induced decline and mortality of silver fir differ among three sites in Southern France Annals of Forest Science 71:643-657 doi:https://doi.org/10.1007/s13595-013-0265-0

Chang W-Y, Lantz VA, MacLean DA (2009) Public attitudes about forest pest outbreaks and control: Case studies in two Canadian provinces Forest Ecology and Management 257:1333-1343 doi:https://doi.org/10.1016/i.foreco.2008.11.031 
Ciesla WM, Donaubauer E (1994) Decline and dieback of trees and forests: A global overview. FAO, Rome, Italy

Der Spiegel (1981) Säureregen: "Da liegt was in der Luft" Der Spiegel 47:96-110

Deuffic P, Arts BJM, Sotirov M (2018) "Your policy, my rationale". How individual and structural drivers influence European forest owners' decisions Land Use Policy 79:1024-1038 doi:https://doi.org/10.1016/i.landusepol.2016.09.021

Deuffic P, Lyser S (2012) Biodiversity or bioenergy: is deadwood conservation an environmental issue for French forest owners? Canadian journal of forest research 42:1491-1502 doi:https://doi.org/10.1139/×2012-073

Deuffic P, Ní Dhubháin Á (2020) Invisible losses. What a catastrophe does to forest owners' identity and trust in afforestation programmes Sociologia Ruralis 60:104-128 doi:https://doi.org/10.1111/soru.12272

Dullinger S, Dirnböck T, Köck R, Hochbichler E, Englisch T, Sauberer N, Grabherr G (2005) Interactions among tree-line conifers: Differential effects of pine on spruce and larch Journal of Ecology 93:948-957 doi:https://doi.org/10.1111/j.1365-2745.2005.01036.x

Dunn RR (2005) Modern Insect Extinctions, the Neglected Majority Conservation Biology 19:10301036 doi:https://doi.org/10.1111/i.1523-1739.2005.00078.x

EAA (European Environment Agency) (2017) Climate change, impacts and vulnerability in Europe 2016. An indicator-based report vol n¹/2017. European Environment Agency, Copenhagen

Fellenor J, Barnett J, Potter C, Urquhart J, Mumford JD, Quine CP (2018) The social amplification of risk on Twitter: the case of ash dieback disease in the United Kingdom Journal of Risk Research 21:1163-1183 doi:https://doi.org/10.1080/13669877.2017.1281339

Ficko A, Lidestav G, Ní Dhubháin Á, Karppinen H, Zivojinovic I, Westin K (2019) European private forest owner typologies: A review of methods and use Forest Policy and Economics 99:21-31 doi:https://doi.org/10.1016/i.forpol.2017.09.010

Grothmann T, Patt A (2005) Adaptive capacity and human cognition: The process of individual adaptation to climate change Global Environmental Change 15:199-213 doi:https://doi.org/10.1016/i.gloenvcha.2005.01.002

Gundersen VS, Frivold LH (2011) Naturally dead and downed deadwood in Norwegian boreal forests: public preferences and the effect of information. Scandinavian Journal of Forest Research 26:110-119 doi:http://dx.doi.org/10.1080/02827581.2010.536567

Gupta J et al. (2010) The Adaptive Capacity Wheel: a method to assess the inherent characteristics of institutions to enable the adaptive capacity of society Environmental Science \& Policy 13:459-471 doi:https://doi.org/10.1016/j.envsci.2010.05.006

Hagerman SM, Pelai R (2018) Responding to climate change in forest management: two decades of recommendations Frontiers in Ecology and the Environment 16:579-587 doi:http://dx.doi.org/10.1002/fee.1974

Hanewinkel M, Cullmann DA, Schelhaas M-J, Nabuurs G-J, Zimmermann NE (2013) Climate change may cause severe loss in the economic value of European forest land Nature Clim Change 3:203-207

doi:http://www.nature.com/nclimate/journal/v3/n3/abs/nclimate1687.html\#supplementary -information

Hansen AJ et al. (2001) Global Change in Forests: Responses of Species, Communities, and Biomes: Interactions between climate change and land use are projected to cause large shifts in biodiversity BioScience 51:765-779 doi:https://doi.org/10.1641/00063568(2001)051[0765:GCIFR0]2.0.CO;2

He J (2017) Looking beyond tenure in China's Collective Forest Tenure Reform: insights from Yunnan Province, Southwest China International Forestry Review 19:29-41 doi:https://doi.org/10.1505/146554817820888609

He J, Zhou Z, Weyerhaeuser H, Xu J (2009) Participatory technology development for incorporating non-timber forest products into forest restoration in Yunnan, Southwest China Forest 
Ecology and Management 257:2010-2016

doi:http://dx.doi.org/10.1016/j.foreco.2009.01.041

He J, Zhou Z, Yang H, Xu J (2011) Integrative Management of Commercialized Wild Mushroom: A Case Study of Thelephora ganbajun in Yunnan, Southwest China vol 48. doi:https://doi.org/10.1007/s00267-011-9691-7

IPCC (2014) Climate Change 2014: Impacts, Adaptation, and Vulnerability. Part A: Global and Sectoral Aspects. Contribution of Working Group II to the Fifth Assessment Report of the Intergovernmental Panel on Climate Change. Cambridge University Press, Cambridge, United Kingdom and New York, NY

Kellomäki S, Karjalainen T, Väisänen H (1997) More timber from boreal forests under changing climate? Forest Ecology and Management 94:195-208 doi:https://doi.org/10.1016/S03781127(96)03975-8

Lausch A, Heurich M, Fahse L (2013) Spatio-temporal infestation patterns of Ips typographus (L.) in the Bavarian Forest National Park, Germany Ecological Indicators 31:73-81 doi:https://doi.org/10.1016/j.ecolind.2012.07.026

Lawrence A (2017) Adapting through practice: Silviculture, innovation and forest governance for the age of extreme uncertainty Forest Policy and Economics 79:50-60 doi:http://doi.org/10.1016/j.forpol.2016.07.011

Lawrence A et al. (2020) Extension, advice and knowledge systems for private forestry: Understanding diversity and change across Europe Land Use Policy 94:104522 doi:https://doi.org/10.1016/j.landusepol.2020.104522

Lidskog R, Sjödin D (2014) Why do forest owners fail to heed warnings? Conflicting risk evaluations made by the Swedish forest agency and forest owners Scandinavian Journal of Forest Research 29:275-282 doi:https://doi.org/10.1080/02827581.2014.910268

Lidskog R, Sjödin D (2015) Risk governance through professional expertise. Forestry consultants' handling of uncertainties after a storm disaster Journal of Risk Research:1-17 doi:https://doi.org/10.1080/13669877.2015.1043570

Lindner M et al. (2014) Climate change and European forests: What do we know, what are the uncertainties, and what are the implications for forest management? Journal of Environmental Management 146:69-83 doi:http://dx.doi.org/10.1016/j.jenvman.2014.07.030

Lindner M et al. (2010) Climate change impacts, adaptive capacity, and vulnerability of European forest ecosystems Forest Ecology and Management 259:698-709 doi:http://dx.doi.org/10.1016/j.foreco.2009.09.023

Lodin I, Eriksson LO, Forsell N, Korosuo A, 11, 346. (2020) Combining Climate Change Mitigation Scenarios with Current Forest Owner Behavior: A Scenario Study from a Region in Southern Sweden Forests 11:346 doi:https://doi.org/10.3390/f11030346

Marzano M, Woodcock P, Quine CP (2019) Dealing with dieback: forest manager attitudes towards developing resistant ash trees in the United Kingdom Forestry: An International Journal of Forest Research 92:554-567 doi:https://doi.org/10.1093/forestry/cpz022

Mason M (2010) Sample Size and Saturation in PhD Studies Using Qualitative Interviews Forum Qualitative Sozialforschung / Forum: Qualitative Social Research 11:1-19

McFarlane BL, Witson DOT (2008) Perceptions of ecological risk associated with mountain pine beetle (Dendroctonus ponderosae) infestations in Banff and Kootenay National Parks of Canada Risk Analysis 28:203-212 doi:https://doi.org/10.1111/j.1539-6924.2008.01013.x

Miles MB, Huberman MA, Saldaña J (2013) Qualitative Data Analysis: A Methods Sourcebook. SAGE Publications, Los Angeles

Millar Cl, Stephenson NL, Stephens SL (2007) Climate change and forests of the future: managing in the face of uncertainty Ecological Applications 17:2145-2151 doi:https://doi.org/10.1890/061715.1 
Müller J, Bütler R (2010) A review of habitat thresholds for dead wood: a baseline for management recommendations in European forests European Journal of Forest Research 129:981-992 doi:http://dx.doi.org/10.1007/s10342-010-0400-5

Nelson $\mathrm{H}$ (2007) Does a crisis matter? Forest policy responses to the mountain pine beetle epidemic in British Columbia Canadian journal of Agricultural Economics 55:459-470 doi:https://doi.org/10.1111/i.1744-7976.2007.00102.x

Palinkas LA, Horwitz SM, Green CA, Wisdom JP, Duan N, Hoagwood K (2015) Purposeful Sampling for Qualitative Data Collection and Analysis in Mixed Method Implementation Research Adm Policy Ment Health 42:533-544 doi:http://dx.doi.org/10.1007/s10488-013-0528-y

Petucco C, Andrés-Domenech P, Duband L (2020) Cut or keep: What should a forest owner do after a windthrow? Forest Ecology and Management 461:117866 doi:https://doi.org/10.1016/j.foreco.2020.117866

Radke N, Yousefpour R, von Detten R, Reifenberg S, Hanewinkel M (2017) Adopting robust decisionmaking to forest management under climate change Annals of Forest Science 74:43 doi:https://doi.org/10.1007/s13595-017-0641-2

Risbey J, Kandlikar M, Dowlatabadi H, Graetz D (1999) Scale, context, and decision making in agricultural adaptation to climate variability and change Mitigation and Adaptation Strategies for Global Change 4:137-165 doi:https://doi.org/10.1023/A:1009636607038

Roberge J-M et al. (2016) Socio-ecological implications of modifying rotation lengths in forestry Ambio 45:109-123 doi: https://doi.org/10.1007/s13280-015-0747-4

Rubel F, Brugger K, Haslinger K, Auer I (2017) The climate of the European Alps: Shift of very high resolution Köppen-Geiger climate zones 1800-2100 Meteorologische Zeitschrift 26:115-125 doi:https://doi.org/10.1127/metz/2016/0816

Sacher P, Mayer M (2019) Szenarien der Waldentwicklung in Bayern bis 2045 und 2075 - Ergebnisse einer Delphi-Studie mit ausgewählten Waldexperten. Institut für Geographie und Geologie der Universität Greifswald, Greifswald, Germany. doi:https://doi.org/10.23689/fidgeo-3258

Sarewitz D (2011) Does climate change knowledge really matter? Wiley Interdisciplinary Reviews: Climate Change 2:475-481 doi:https://doi.org/10.1002/wcc.126

Seibold S et al. (2016) Microclimate and habitat heterogeneity as the major drivers of beetle diversity in dead wood Journal of Applied Ecology 53:934-943 doi:https://doi.org/10.1111/13652664.12607

Slovic P (1987) Perception of risk Science New Series, Vol. 236, :280-285

Sousa-Silva R et al. (2018) Adapting forest management to climate change in Europe: Linking perceptions to adaptive responses Forest Policy and Economics 90:22-30 doi:https://doi.org/10.1016/i.forpol.2018.01.004

Staupe-Delgado R (2019) Progress, traditions and future directions in research on disasters involving slow-onset hazards Disaster Prevention and Management: An International Journal 28:623635 doi:https://doi.org/10.1108/DPM-11-2018-0358

Strauss A, Corbin J (1994) Grounded theory methodology. In: Denzin NK, Lincoln YS (eds) Handbook of qualitative research. SAGE Publications Ltd, Thousand Oaks, pp 273-285

Takala T, Hujala T, Tanskanen M, Tikkanen J (2019) Competing discourses of the forest shape forest owners' ideas about nature and biodiversity conservation Biodiversity and Conservation 28:3445-3464 doi:https://doi.org/10.1007/s10531-019-01831-7

Van Gameren V, Zaccai E (2015) Private forest owners facing climate change in Wallonia: Adaptive capacity and practices Environmental Science and Policy 52:51-60 doi:https://doi.org/10.1016/j.envsci.2015.05.004

Van Herzele A, Van Gossum P (2008) Typology building for owner-specific policies and communications to advance forest conversion in small pine plantations Landscape and Urban Planning 87:201-209 doi:https://doi.org/10.1016/j.landurbplan.2008.06.003

Weber EU (2010) What shapes perceptions of climate change? Wiley Interdisciplinary Reviews: Climate Change 1:332-342 doi:https://doi.org/10.1002/wcc.41 
925 Weiss G et al. (2019) Forest ownership changes in Europe: State of knowledge and conceptual foundations Forest Policy and Economics 99:9-20 doi:https://doi.org/10.1016/i.forpol.2018.03.003

Wilson RS, Zwickle A, Walpole H (2019) Developing a Broadly Applicable Measure of Risk Perception Risk Analysis 39:777-791 doi:https://doi.org/10.1111/risa.13207 adaptation strategies in forest management under climate change Annals of Forest Science 74:40 doi:https://doi.org/10.1007/s13595-017-0640-3 